\title{
BCC stabilization and Growth Stress Behavior in Ti/V Multilayers
}

\author{
Li Wan, Gregory Thompson* \\ Department of Metallurgical Engineering, The University of Alabama, Tuscaloosa, \\ AL 35487-0202, USA
}

Corresponding author: gthompson@eng.ua.edu

\begin{abstract}
As the length scale decreases, materials can undergo size-dependent phase changes. This work explores the hcp to bcc Ti transformations in $\mathrm{Ti} / \mathrm{V}$ multilayers of equal volume fraction. A series of $\mathrm{Ti} / \mathrm{V}$ multilayers were sputter-deposited and revealed a transition at $\sim 1 \mathrm{~nm}$ Ti. This length scale stability is explained through a series of in situ growth stress measurements that are correlated to the epitaxial orientation of the $\mathrm{Ti}$ and $\mathrm{V}$ growth directions with respect to each other within the multilayer. It was found the hcp Ti undergoes in-plane compression while bcc V undergoes in-plane tension. It is believed that the interplay of large misfit strain and the surface energy driven intermixing, quantified by atom probe tomography, contributes to the stabilization of bec Ti.
\end{abstract}

Keywords: in situ growth stress; phase transformation; Ti/V; multilayered thin films

\section{Introduction}

When the size of a material is reduced, the crystal structure can change. This has been an area of active investigation for various thin films and multilayered thin film structures [1-3]. Such length scale dependent phase transformations can enable exceptional material properties for new devices with tailored functionality [4-6]. Since the interfacial-to-volumetric ratios of these types of material can be quite large, the structural and chemical nature of the interfaces is paramount. These surfaces can be modified through the sequence of deposition of different contact compositions and deposition energies [7]. In addition, these thin films can experience significant stress states during the growth that exceed elasticity limits for their bulk counterparts [8-10]. The interconnection of phase equilibrium, intrinsic growth stresses, and the stability of an interfacial compositional gradient in thin films is a fertile area of research. 
Two general approaches have been used to model phase stability in thin films. The coherency model developed by Bruinsma and Zangwill [11,12] describes pseudomorphism as local minima in the free energy density function. As the film thickness is reduced, epitaxial strains created by the film matching a substrate raises the energy of the crystal; however, a crystallographic transformation to a new phase can lower the energy to this local minima and provide a metastable condition for the film. This model was explicitly developed for a thin film on a rigid substrate (single interface) in which a single transformation occurs. A series of stability maps for this transformation were then proposed based upon the strain.

Unlike a single film in contact with one interface, in a multilayered structure, the film is in contract with two interfaces - one below and above the film - and these growth surfaces may not necessarily be rigid. Furthermore, having more than one film within the stack provides opportunities for multiple transformations in the different layers that can affect the phase stability behavior. Dregia et al. [13-16] proposed a classical thermodynamic model to explain these phase transformations in a two species multilayer stack. Here the competition between volumetric and interfacial energy was used to describe phase stability in a repeating bilayer. As one or both layers were reduced in thickness (or equivalently volume for a fixed surface area), the interfacial energy reduction for a phase change between the different layers becomes comparable or even larger than that of the bulk free energy penalty for such a transformation. Thus, for sufficiently thin layers, the interfacial energy reduction can thermodynamically drive a change in phase and has been applied to various multilayer systems $[17,18]$.

In respect to the system type studied in this paper, Ti has been reported to undergo a hcp to bcc transformations in $\mathrm{Ti} / \mathrm{Nb}$ multilayers $[15,17]$. It was found in this system that the bcc transformed $\mathrm{Ti}$ layer revealed a significant amount of $\mathrm{Nb}$ interdiffusion which provided an additional chemical stabilizing effect on the transformation layer thickness when rationalized by the thermodynamic model described above [15,17]. The most recent investigation of $\mathrm{Ti} / \mathrm{Nb}$ stability have involved the use of in situ stress measurements which noted a change in tensile-tocompressive stress at the bcc-to-hcp transition [17]. The use of such real-time measurements, particularly the stress evolution of a thin film, provides new insights into the relationship of how phase stability influences adatom mobility during film growth. 
The stress evolution for a thin film is generally accepted as the following: In the first stage of growth, where adatoms forming embryonic islands, a compressive stress results [19,20]. A subsequent tensile stress is then generated from the coalescence of these islands to minimize the grain boundary energy. Elemental films with low atomic mobility then tend to retain this tensile condition while adatoms with higher intrinsic mobility exhibit a return to compressive stress in the post coalescence condition, though the exact mechanism of post-coalescence compressive stress is still a matter of much discussion [21-24]. How these stress states could be altered when the film is undergoing a change in phase has been less studied.

As described by the prior stability models, strain (hence stress) is intimately related to phase stability as well as the thermodynamic energies for determining phase stability. Monitoring intrinsic growth stresses in real time can provide for a deeper understanding in the connection between the strain-induced and thermodynamic based phase stability concepts. Though Shull and Spaepen [25] have reported one of the earliest uses of in situ measurements from a multilayered film, the paper focused on the growth of $\mathrm{Ag} / \mathrm{Cu}$. Both of these films are face centered cubic (fcc) and a transformation would not necessarily be expected. To the authors' knowledge, the use in situ stress evolution and its connection with phase stability has only been explicitly reported in $\mathrm{Ti} / \mathrm{Nb}[17]$.

This research aims on furthering the investigations of in situ stress behavior and its relationship to phase stability. In this paper, we explore the growth stresses for the allotropic hcp-to-bcc Ti phase transformation in Ti/V multilayers. Unlike the prior Ti/Nb investigation [17], where $\beta$-Ti, the high temperature allotrope bcc Ti phase, has near equivalent lattice spacing to bcc $\mathrm{Nb}(0.330 \mathrm{~nm})$, this new bcc $\mathrm{V}$ template offers a considerable difference in lattice matching. The $\beta$-Ti lattice parameter is $\sim 0.327 \mathrm{~nm}$, extrapolated to room temperature [17], where bcc $\mathrm{V}$ is $\sim 0.303 \mathrm{~nm}$, which would generate considerably more strain at the interface and influence the adatom mobility behavior that is manifested in the stress measurements. Under such conditions, the growth stress states should be altered and provide new insights into Ti's stabilization from which a better understanding between by interfacial energy reduction and strain can be developed. This comparative study to the former work will bridge our knowledge gaps between strain induced and thermodynamic driven phase transformations. 


\section{Experimental Details}

The Ti/V multilayered thin films with equivalent individual layer thicknesses were sputter-deposited at ambient temperature $\left(\sim 25{ }^{\circ} \mathrm{C}\right)$ from $>99.95 \%$ pure elemental targets onto [001] Si substrates to a thickness of $\sim 200 \mathrm{~nm}$. The bilayer thickness (sum of the individual layer thickness) ranged from $40 \mathrm{~nm}$ to $2 \mathrm{~nm}$. i.e. $20 \mathrm{~nm} / 20 \mathrm{~nm}, 10 \mathrm{~nm} / 10 \mathrm{~nm}, 5 \mathrm{~nm} / 5 \mathrm{~nm}, 2 \mathrm{~nm} / 2 \mathrm{~nm}$, $1 \mathrm{~nm} / 1 \mathrm{~nm}$, with Ti being the first layer of the bilayer to be deposited onto the native oxide surface. The base vacuum pressure prior deposition was $<10^{-8}$ Torr. For sputtering, ultra-high purity Argon was flowed as the working gas at 10 standard cubic centimeters per minute flow rate to a pressure of 2 mTorr.

During the deposition of the thin films, the in situ stress evolution was monitored using $k$ Space Associates $\left(\mathrm{kSA}^{\circledR}\right)$ Muti-beam Optic Sensor (MOS). The MOS system works by measuring the wafer curvature with real-time feedback. 2D laser spot arrays are reflected off the sample surface and as the wafer bends (or curves) in response to the growth stresses, the spot positions change. Using this in-plane displacement, the wafer curvature is measured and the stress determined by the classic Stoney equation given below [26]:

$$
\sigma_{f} \cdot t_{f}=\frac{E_{s} t_{s}^{2}}{6\left(1-v_{s}\right)}\left(\frac{1}{R}-\frac{1}{R_{0}}\right)
$$

where $\sigma_{f} \cdot t_{f}$ (also known as stress-thickness product) is the surface stress [27] for the film growth, $E_{s}$ and $v_{s}$ are the Young's modulus and the Poisson ratio of the substrate, respectively, $t_{s}$ is the thickness of the substrate, $1 / R$ and $1 / R_{0}$ are measured curvatures after and before the deposition. Further experimental details can be found in reference [17].

The deposition rates of $\mathrm{Ti}$ and $\mathrm{V}$ were determined by dividing the film thickness, measured from X-Ray Reflectivity (XRR) [28] and confirmed by the Transmission Electron Microscopy (TEM) cross-sectional micrographs, by the deposition time. XRR was performed on an X'pert Philips diffractometer operated with $\mathrm{Cu} \mathrm{K}_{\alpha}$ radiation $(\lambda=1.5406 \AA)$ at $40 \mathrm{kV}$ and 30 $\mathrm{mA}$. The growth rates of Ti and V were $0.029 \mathrm{~nm} / \mathrm{s}$ and $0.031 \mathrm{~nm} / \mathrm{s}$, respectively.

A series of $\theta-2 \theta$ scans of X-Ray Diffraction (XRD) was conducted ex situ on the same Philips diffractometer using the same operating settings. These scans provided for phase 
identification of the post deposited films. Selected area electron diffraction patterns (SAED) were also taken from thin plan-view and cross-sectional foils in the FEI Tecnai F20 (S)TEM to further examine the phase constitutions of each film. The plan-view foils were prepared by conventional TEM sample preparation method through cutting, polishing, dimpling and ion milling. The foil was a $3 \mathrm{~mm}$ disc with a small hole in the middle where electron transparent perforations were around the hole. Theses collected diffraction patterns, together with XRD results, provided phase identification and preferential growth orientation of the films. Crosssectional TEM foils were prepared by Focused Ion Beam (FIB) lift out technique [29] followed by a $5 \mathrm{kV}$ clean up step to reduce any $\mathrm{Ga}^{+}$implantation on the foil surface using the FEI Quanta 3D dual beam FIB-SEM. Bright Field (BF) images were taken to reveal the layered structure of the multilayers. Fast Fourier Transformation (FFT) was generated on the high resolution TEM BF images to examine the orientation relationship between the two adjacent layers.

The multilayers were also characterized by atom probe tomography (APT) performed on a Cameca Scientific Instruments Local Electrode Atom Probe (LEAP®) 3000XSi. The atom probe tips were prepared by a FIB lift out technique [30] and were sharpened into the needle-like shape, with a $5 \mathrm{kV}$ clean-up step to reduce $\mathrm{Ga}+$ implantation into the tip surface. The atom probe tips were analyzed at a base temperature of $40 \mathrm{~K}, 0.2 \mathrm{~nJ}$ laser pulse energy (wavelength $532 \mathrm{~nm}$ ) and repetition rate of $200 \mathrm{kHz}$ in laser mode. The reconstructions of the data was performed on IVAS 3.6.8 software. The mode of reconstruction was based on the 'Tip Profile' mode, as this approach takes into account the shank evolution and the different evaporation fields in multilayered samples [31].

\section{Experimental Results}

As the Ti was reduced in thickness in the Ti/V stack, a change in the XRD peak pattern was noted, Fig. 1. At larger layer thicknesses, two independent peaks can be identified for the hcp Ti and bcc V phases. For sufficiently thin layers, satellite reflection that originate from the superlattice structure of the multilayer can be observed around each of the fundamental phase peaks, denoted by the arrow insets in the figure. These fundamental phase peaks were indexed as hcp Ti (0002) (38.4 ${ }^{\circ}$, ICDD 00-04401294) and bcc V (110) (42.2 , ICDD 00-02201058). For the $2 \mathrm{~nm} / 2 \mathrm{~nm}$ and $1 \mathrm{~nm} / 1 \mathrm{~nm}$ multilayer, only one main peak was diffracted. This could suggest a 
phase transformation; however identifying the phase transition is ambiguous by simply examining a single reflection that does not match either of the previous 'bulk' peaks.

Fig. 2(a)-(c) show SAED patterns taken from $10 \mathrm{~nm} / 10 \mathrm{~nm}, 2 \mathrm{~nm} / 2 \mathrm{~nm}$ and $1 \mathrm{~nm} / 1 \mathrm{~nm}$ multilayers respectively. In this orientation, multiple reflections can be seen and provide a more definitive phase identification. As seen in these patterns, the $10 \mathrm{~nm} / 10 \mathrm{~nm} \mathrm{Ti} / \mathrm{V}$ film has distinctive hep Ti rings, $\{10 \overline{10}\}$ and $\{1 \overline{12} 0\}$, indicating the 'bulk' phase of this multilayer and is in agreement with the fiber texture identification of this phase in the prior XRD results. The $2 \mathrm{~nm} / 2$ nm Ti/V multilayer, as shown in Fig. 2(e), also has a $\{10 \overline{10}\}$ ring (though its intensity appears smeared or hazy) and the $\{11 \overline{2} 0\}$ ring is not evident. Upon reducing the bilayer to $1 \mathrm{~nm} / 1 \mathrm{~nm}$, only a series of reflections that can be consistently indexed to a single bcc phase is noted. Hence, the electron diffraction confirms the hcp-to-bcc transition for $\mathrm{Ti}$ at the thinnest spacing, with an equivalent lattice spacing for both bcc phases. Since the XRD fiber texture has changed in a similar manner between the $1 \mathrm{~nm} / 1 \mathrm{~nm}$ and $2 \mathrm{~nm} / 2 \mathrm{~nm}$ multilayers, it is possible that some portion of the Ti layers for the $2 \mathrm{~nm} / 2 \mathrm{~nm}$ multilayer may contain isolated regions of bcc $\mathrm{Ti}$ along with the clearly identified hcp Ti phase. This conclusion is drawn from the thinnest layer's electron diffraction, where only equivalent bcc rings were noted, but each of these films showed the same XRD fiber orientation. The in-plane grain size varied from approximately 20 to $50 \mathrm{~nm}$ in each of the films, Fig. 2(d)-(f).

It is well known that Ti-V alloy [32] exhibits a Burgers orientation relationship [33], i.e. $<11 \overline{2} 0>_{\alpha} / /<111>_{\beta} ;\{0001\}_{\alpha} / /\{011\}_{\beta}$. With the growth directions verified by XRD above, i.e. the closest packed planes parallel with each other in the growth direction, the in-plane directions were determined by diffraction taken in the cross-section view. In the $10 \mathrm{~nm} / 10 \mathrm{~nm}$ multilayer, we can see fairly abrupt interfaces, Fig. 3(a). Using the lattice fringe images from each layer, Fig. 4(b), a FFT for each layer was obtained, Fig. 3(c)-(e). These patterns reveal the associated planes and directions. Ratios of the principle spot spacings as well as the angles between the principle planes normal were calculated and consistently indexed to either $\alpha$-hcp Ti $<2110>$ zone axis or the bcc $\mathrm{V}<\overline{1} 11>$. Using the FFT from the distinct layers, overlapped spots in the collective pattern were distinctly identified to each phase. The two phases' pattern symmetry with respect to each other confirmed the Burgers orientation relationship, shown in Fig. 3(f). 
The in situ stress evolution for the Ti/V multilayers are shown in Fig. 4(a), with the stress-thickness product plotted as a function of film thickness. For films with a negative slope, this is indicative of compressive stress whereas a positive slope indicates tensile growth. The 'sinusoidal' variation of slopes within one curve represent the growth of one layer on the other. There are three observations to be made from the stress behavior. First, all the films exhibit a large magnitude of an overall compressive stress condition in the post-coalescence regime [2124]. Second, as the bilayer thickness decreases, the overall stress has a trend of becoming more compressive; however, the $1 \mathrm{~nm} / 1 \mathrm{~nm}$ film exhibits an exception to this behavior with its overall compressive stress reduced as compared to the previously thicker bilayers. Interestingly, this 1 $\mathrm{nm} / 1 \mathrm{~nm}$ multilayer also initially grows with a tensile stress until the overall film is $\sim 20 \mathrm{~nm}$ after which the film is compressive. And third, Ti has an overall compressive behavior during its growth (negative slope) in the 'sinusoidal' modulation while $\mathrm{V}$ exhibits an opposite growth stress behavior (positive slope).

Magnified images of specific growth regions between $\mathrm{Ti}$ and $\mathrm{V}$ multilayers are plotted in Fig. 4(b), 4(c), $\mathbf{4 ( d )}$ and $\mathbf{4}(\mathbf{e})$ for the $20 \mathrm{~nm} / 20 \mathrm{~nm}, 10 \mathrm{~nm} / 10 \mathrm{~nm}, 5 \mathrm{~nm} / 5 \mathrm{~nm}$ and $2 \mathrm{~nm} / 2 \mathrm{~nm}$ multilayers, respectively. For the $20 \mathrm{~nm} / 20 \mathrm{~nm}$ thin film (Fig. 4(b)), the Ti first grows tensile up to $\sim 4 \mathrm{~nm}$ with a slope of $\sim 0.6 \mathrm{GPa}$ and then reverts to a compressive growth stress with a slope of $\sim-1.0 \mathrm{GPa}$ for larger thicknesses. The V film exhibits a slightly positive slope $(\sim 0.1 \mathrm{GPa})$ for its growth throughout its $20 \mathrm{~nm}$ thickness. For the $10 \mathrm{~nm} / 10 \mathrm{~nm}$ thin film (Fig. 4(c)), the growth stress for the first $2.5 \mathrm{~nm}$ of Ti has a tensile slope ( $\sim 0.5 \mathrm{GPa})$ whereas a compressive slope $(\sim-0.8 \mathrm{GPa})$ is then noted to occur for a larger thickness. The V film in this multilayer retains the positive growth stress slope $(\sim 0.2 \mathrm{GPa})$. As the layer thicknesses decreases to $5 \mathrm{~nm} / 5$ nm (Fig. 4(d)), Ti's positive growth slope ( $0.8 \mathrm{GPa})$ only occurs over the first $\sim 1 \mathrm{~nm}$ and then exhibits the compressive growth stress with a slope of $\sim-1.5 \mathrm{GPa}$. V retains a slightly positive growth stress of $\sim 0.1 \mathrm{GPa}$. The data collection for the initial Ti growth in the $2 \mathrm{~nm} / 2 \mathrm{~nm}$ multilayer was to noisy to defiantly state if the tensile growth was evident; however the compressive growth stress is apparent revealed by the negative slope of $\sim-1.7$ GPa, Fig. 4(e). The $\mathrm{V}$ again retains a slightly tensile or positive growth slope of $\sim 0.1 \mathrm{GPa}$. The $1 \mathrm{~nm} / 1 \mathrm{~nm}$ did not reveal any discernable changes in slope between the layers as noted in Fig. 4(b). The dependency for the different tensile slope conditions for $\mathrm{Ti}$ are discussed in the proceeding section. 
Finally, to reveal the extent of intermixing within the multilayers, a series of atom probe compositional profiles were taken from the $10 \mathrm{~nm} / 10 \mathrm{~nm}, 5 \mathrm{~nm} / 5 \mathrm{~nm}, 2 \mathrm{~nm} / 2 \mathrm{~nm}$, and $1 \mathrm{~nm} / 1 \mathrm{~nm}$ films, Fig. 5(a)-(d). The 1D profile plots out the composition along the depth direction at a fixed increment of $0.3 \mathrm{~nm}$. The radius of all the regions of interest were set as $2 \mathrm{~nm}$ while the length varies from sample to sample depending on the size of the run. The direction is to be as perpendicular to the interfaces as possible. The growth direction of the thin film and the depth direction are opposite. Intermixing was noted in all four multilayers. Interestingly, for the thicker bilayers with the clearly discernable bulk phases, $\mathrm{V}$ was found to be throughout the Ti layer where Ti was not found to be throughout the $\mathrm{V}$ layer, Fig. 5(a)-(b). The extent of V intermixing in the Ti increased with decreasing bilayer spacing, Table 1 . Once the bilayer was 2 $\mathrm{nm} / 2 \mathrm{~nm}$ and $1 \mathrm{~nm} / 1 \mathrm{~nm}$, Fig. 5(c)-(d), intermixing of both species in each layer was present and a sinusoidal chemical modulation is seen. Even though the $1 \mathrm{~nm} / 1 \mathrm{~nm}$ film is bcc, it is technically not a solid solution evident by the chemical modulations in the film.

\section{Discussion}

Prior literature has reported that in a multilayered thin film with two dissimilar materials with a large lattice mismatch, significant stresses and strains can be manifested in the individual film layers [34,35]. This results in lattice distortions. One can also consider the influence of an underlying substrate where epitaxy can also contribute to lattice film distortion. However, these multilayers were deposited onto a Si wafer which had a native amorphous silica surface with no preferred crystalline structure in contact with the deposited film. Moreover, the films were grown at ambient temperature limiting the mobility for any epitaxial growth from the substrate. Hence, the change in strain for these multilayers are most likely associated with the newly deposited metallic interfaces between the layers as the bilayers were repeatedly grown and stacked on top of each subsequent layer. Based on the XRD configuration shown in Fig. 1, this measurement is sensitive to lattice planes and strains perpendicular to the $x-y$ plane or in-plane condition of the film, i.e. in the thin film's growth direction. This orientation reveals a clear fiber texture for the $\{0002\}$ and $\{110\}$ planes for the hcp and bcc bulk phases respectively. These surfaces are the closest packed planes with the lowest surface energy. Using these peaks, we will determine the amount of strain associated with these specific lattice planes in the z- or growth direction. In 
general, as the bilayer thickness was reduced from $20 \mathrm{~nm} / 20 \mathrm{~nm}$ to $5 \mathrm{~nm} / 5 \mathrm{~nm}$, the Ti $\{0002\}$ peak shifted to a higher $2 \theta$ value whereas the $\mathrm{V}\{110\}$ peak shifted to a lower $2 \theta$ value. This is tabulated in Table 2, where the strain reported was calculated from

$$
\varepsilon=\frac{d_{1}-d_{0}}{d_{1}} \times 100 \%
$$

where $d_{1}$ is the calculated the lattice spacing from the peak position and $d_{0}$ is the 'strain-free' lattice spacing referenced from the $20 \mathrm{~nm} / 20 \mathrm{~nm}$ multilayer. As the bilayer thickness decreases, the two individual phases appear to mechanical respond to the other with Ti out-of-plane spacing becoming compressive and $\mathrm{V}$ tensile. The strain values are relatively similar, with the absolute value of $\mathrm{V}$ being slightly higher than Ti. This difference is attributed to Ti [0002] being slightly stiffer than V [110] direction V [36,37].

For the $1 \mathrm{~nm} / 1 \mathrm{~nm}$ multilayer, the electron diffraction confirmed the bcc phase for both $\mathrm{Ti}$ and V. In this case, the reported pseudomorphic bcc/bcc strain is an order of magnitude larger than the bulk phase strains. For the $2 \mathrm{~nm} / 2 \mathrm{~nm}$ multilayer, the phase identification is somewhat ambiguous. The electron diffraction indicated evidence of hcp Ti while the significant change in fiber texture, similar to the $1 \mathrm{~nm} / 1 \mathrm{~nm}$ multilayer, could be suggestive of a bcc transition. We have tabulated both phases in Table 2. Either way, once bcc Ti forms, as evident in the $1 \mathrm{~nm} / 1$ $\mathrm{nm}$ multilayer, both phases significantly strain.

As the film's bilayer is reduced, the overall compressive stress increased (except for the 1 $\mathrm{nm} / 1 \mathrm{~nm}$ multilayer, which will be treated separately). This increased compressive stress is attributed to the increasingly negative compressive slope of the Ti's growth while the $\mathrm{V}$ growth slope was relatively constant. What is particularly interesting is that the hcp growth texture, $\{0002\}$, reveals a compressive strain, which would imply a corresponding tensile response in the growth plane. However, the majority of the film's growth is compressive. To reconcile this behavior, one must recall that the in situ stress measurements are a collection of both individual crystal behavior as well as the influence of adatom mobility on the growth conditions and microstructure of the film. By noting the crystal response above, we can conclude that the adatom behavior for the growing film appears to dominate the collective film's stress response. 
In the early stages of Ti's growth, the Ti layer does reveal initial tensile stress, Fig. 4. This could be attributed to the intermixing of $\mathrm{V}$ into the Ti layer influencing the adatom mobility. From Table 1, the extent of the intermixing width between the interfaces is similar to the length scales over which the tensile slope formed. The intermixed width was defined as the length over which the compositional profile changed by more than 5 at. \%. This intermixed region (Table 1) as well as the growth length of the initial tensile response (Fig. 4) similarly trend, e.g. as the bilayer thickness reduced, the intermixing width and length of tensile stress reduced. The influence of intermixing in regulating the stress states of films has been noted by others [38]. Once the V content is reduced, the Ti layer is able to exhibit post-coalescence compressive stress behavior consistent with its prior report [39].

The asymmetric intermixing width between Ti grown on $\mathrm{V}$ and $\mathrm{V}$ grown on Ti gives insights into the possible driving forces that lead to intermixing. First, the surface energy of $\mathrm{V}$ is slightly larger than $\mathrm{Ti}\left(2.88 \mathrm{~J} / \mathrm{m}^{2}\right.$ vs. $\left.2.57 \mathrm{~J} / \mathrm{m}^{2}\right)$ [40]. As $\mathrm{V}$ grows on the Ti surface, Ti would preferably exchange with $\mathrm{V}$ to lower the surface energy. This can drive intermixing between the layers with the $\mathrm{V}$ on Ti being more intermixed. This type of surface exchange mechanism during growth was simulated and experimentally verified for a $\mathrm{Cu} / \mathrm{CoFe}$ mulailyer interface [41]. Secondly, the diffusion coefficient of $\mathrm{V}$ in $\alpha$-Ti is two orders of magnitude higher than that of $\mathrm{Ti}$ in $\mathrm{V}[42,43]$. Thus it is easier for $\mathrm{V}$ to quickly diffuse through the Ti layers. This significant diffusivity difference may also explain why $\mathrm{V}$ is able to completely intermix through the thicker Ti layers seen in Fig. 5. $\mathrm{V}$ has been reported to have a few at. \% solubility within $\alpha$-Ti near room temperature [44]. Finally, for the confirmed bcc Ti in the $1 \mathrm{~nm} / 1 \mathrm{~nm}$ (and suspected 2 $\mathrm{nm} / 2 \mathrm{~nm}$ ) multilayer, $\mathrm{V}$ is a beta stabilizer and exhibits complete solubility between both species at high temperatures [45,46]. In this case, the amount of intermixing in both layers is acceptable and may explain why higher amounts of each species is present in each of the layers. As the extent of intermixing increased in each layer, the corresponding width of intermixing decreased as more of each species was incorporated into the other layer.

For the $1 \mathrm{~nm} / 1 \mathrm{~nm}$ multilayer, the cumulative stress response for the film was markedly different than any of the other films grown. Using the atom probe data from Table 1, we can quantify that the intermixed width was on the same length scale as the layers themselves. Even though the film shows a chemical modulation, this chemical layering was insufficient to reveal a 
clear change in stress for each layer. Consequently, the compressive stress was reduced because there was no clear Ti layer which was previously shown to drive the overall compressive stress of the film by its negative slope. The mixed nature of this film also yielded a pronounced change in adatom mobility. The film exhibited a classical compressive-tensile-compressive stress response with thickness which is commonly noted in single phase films [47], though the lengths scale over which these transitions spans was larger. Though the $2 \mathrm{~nm} / 2 \mathrm{~nm}$ multilayer exhibited the same growth texture (and similar intermixing) as this $1 \mathrm{~nm} / 1 \mathrm{~nm}$ film, the ability for it to retain some amount of hcp phase appears to help mitigate these growth stress changes. Thus, the change in growth stress may have to do more with phase, than intermixing and growth texture.

\section{Conclusions}

A series of Ti/V multilayered thin films with varying bilayer thickness have been sputterdeposited onto [001] Si substrates. As the bilayer thickness was reduced from $20 \mathrm{~nm} / 20 \mathrm{~nm}$ to 2 $\mathrm{nm} / 2 \mathrm{~nm}$, the overall compressive stress reduced. This was contributed to Ti having a significant compressive growth stress slope as compared to the slightly tensile growth stress of V. For larger bilayer thicknesses, the initial $\mathrm{Ti}$ growth was tensile but reverted to a compressive stress at a thickness value dependent on the bilayer spacing. This initial Ti tensile stress is believed to be associated with the intermixing of $\mathrm{V}$ with Ti upon its initial growth, as the intermixing also was a function of the bilayer spacing.

The $20 \mathrm{~nm} / 20 \mathrm{~nm}$ to $5 \mathrm{~nm} / 5 \mathrm{~nm}$ bilayer films revealed XRD texture peaks consistent of each individual bulk phase, with each phase experiencing increasing strain with decreasing bilayer spacing. Cross-sectional electron diffraction confirmed the Burgers orientation relationship between the phases. For the $2 \mathrm{~nm} / 2 \mathrm{~nm}$ and $1 \mathrm{~nm} / 1 \mathrm{~nm}$ bilayers, these individual XRD phase peaks were replaced by a single fiber textured peak that was in between the two peaks. However, the electron diffraction confirmed hcp Ti within the $2 \mathrm{~nm} / 2 \mathrm{~nm}$ bilayer and only a single bcc phase for the $1 \mathrm{~nm} / 1 \mathrm{~nm}$. It is suspected that the $2 \mathrm{~nm} / 2 \mathrm{~nm}$ multilayer, based on the similar XRD fiber texture as the $1 \mathrm{~nm} / 1 \mathrm{~nm}$ multilayer, likely consisted of bcc and hcp Ti.

Upon stabilizing bcc Ti for the $1 \mathrm{~nm} / 1 \mathrm{~nm}$ multilayer, the growth of film behavior did not show the separate elemental growth of the Ti and V and the compressive stress was significantly 
reduced. Atom probe tomography confirmed a compositional modulation within this film; however, the intermixing width for this thinnest multilayer was on the same size as the individual layer thicknesses. This created a film that exhibited a classical compressive-to-tensile-to compressive stress evolution as it grew albeit it over a larger film thickness as compared to a single element layer growth.

\section{Acknowledgements}

This work has been supported by the National Science Foundation (Grant NSF-DMR1207220). The authors thank the Central Analytical Facility in the University of Alabama for support.

\section{Reference}

[1] R. Hoogeveen, M. Moske, H. Geisler, K. Samwer, Thin Solid Films 275 (1996) 203.

[2] P. Boher, F. Giron, P. Houdy, P. Beauvillain, C. Chappert, P. Veillet, J. Appl. Phys. 70 (1991) 5507.

[3] W. Vavra, D. Barlett, S. Elagoz, C. Uher, R. Clarke, Physical Review B 47 (1993) 5500.

[4] A.A. Tonkikh, E.N. Voloshina, P. Werner, H. Blumtritt, B. Senkovskiy, G. Guntherodt, S.S. Parkin, Y.S. Dedkov, Sci. Rep. 6 (2016) 23547.

[5] K.M. Shahil, A.A. Balandin, Solid State Commun. 152 (2012) 1331.

[6] Y. Feng, S.L. Burkett, Journal of Vacuum Science \& Technology B 33 (2015) 022004.

[7] R.Q. Hwang, M.C. Bartelt, Chem. Rev. 97 (1997) 1063.

[8] R. Koch, Journal of Physics: Condensed Matter 6 (1994) 9519.

[9] A. Miyamura, K. Kaneda, Y. Sato, Y. Shigesato, Thin Solid Films 516 (2008) 4603.

[10] C. Chuang, C. Chao, R. Chang, K. Chu, J. Mater. Process. Technol. 201 (2008) 770.

[11] R. Bruinsma, A. Zangwill, Journal de physique 47 (1986) 2055. 
[12] R. Bruinsma, A. Zangwill, EPL (Europhysics Letters) 4 (1987) 729.

[13] S. Dregia, R. Banerjee, H. Fraser, Scr. Mater. 39 (1998) 217.

[14] G. Thompson, R. Banerjee, S. Dregia, H. Fraser, Acta materialia 51 (2003) 5285.

[15] G. Thompson, R. Banerjee, S. Dregia, M. Miller, H. Fraser, J. Mater. Res. 19 (2004) 1582.

[16] J. Li, W. Liu, Q. Jiang, Acta materialia 53 (2005) 1067.

[17] L. Wan, X. Yu, G.B. Thompson, Acta Materialia 80 (2014) 490.

[18] L. Wan, X. Yu, X. Zhou, G. Thompson, J. Appl. Phys. 119 (2016) 245302.

[19] C. Friesen, C. Thompson, Phys. Rev. Lett. 93 (2004) 056104.

[20] R. Cammarata, T. Trimble, D. Srolovitz, J. Mater. Res. 15 (2000) 2468.

[21] G. Abadias, A. Fillon, J.J. Colin, A. Michel, C. Jaouen, Vacuum 100 (2014) 36.

[22] A. González-González, C. Polop, E. Vasco, Phys. Rev. Lett. 110 (2013) 056101.

[23] C. Pao, S.M. Foiles, E.B. Webb III, D.J. Srolovitz, J.A. Floro, Phys. Rev. Lett. 99 (2007) 36102 .

[24] J.W. Shin, E. Chason, Phys. Rev. Lett. 103 (2009) 056102.

[25] A.L. Shull, F. Spaepen, J. Appl. Phys. 80 (1996) 6243.

[26] G.G. Stoney, Proceedings of the Royal Society of London. Series A, Containing Papers of a Mathematical and Physical Character (1909) 172.

[27] J. Vermaak, C. Mays, D. Kuhlmann-Wilsdorf, Surf. Sci. 12 (1968) 128.

[28] Y. Sasanuma, M. Uchida, K. Okada, K. Yamamoto, Y. Kitano, A. Ishitani, Thin Solid Films 203 (1991) 113.

[29] L. Giannuzzi, F. Stevie, Micron 30 (1999) 197.

[30] K. Thompson, D. Lawrence, D. Larson, J. Olson, T. Kelly, B. Gorman, Ultramicroscopy 107 (2007) 131.

[31] D.J. Larson, T.J. Prosa, R.M. Ulfig, B.P. Geiser, T.F. Kelly, Local Electrode Atom Probe Tomography, Springer, 2014. 
[32] R. Banerjee, P. Collins, D. Bhattacharyya, S. Banerjee, H. Fraser, Acta Materialia 51 (2003) 3277.

[33] D. Bhattacharyya, G.B. Viswanathan, R. Denkenberger, D. Furrer, H.L. Fraser, Acta Materialia 51 (2003) 4679.

[34] J. Stevens, R. Hwang, Phys. Rev. Lett. 74 (1995) 2078.

[35] V. Srikant, J. Speck, D. Clarke, J. Appl. Phys. 82 (1997) 4286.

[36] D. Tromans, Int.J.Res.Rev.Appl.Sci 6 (2011) 462.

[37] Y. Liu, H. Zhou, Y. Zhang, J. Nucl. Mater. 416 (2011) 345.

[38] B. Clemens, W. Nix, V. Ramaswamy, J. Appl. Phys. 87 (2000) 2816.

[39] J.A. Thornton, D.W. Hoffman, Journal of Vacuum Science \& Technology 14 (1977) 164.

[40] L. Mezey, J. Giber, Jpn.J.Appl.Phys 21 (1982) 1569.

[41] X. Zhou, H. Wadley, R.A. Johnson, D. Larson, N. Tabat, A. Cerezo, A. Petford-Long, G. Smith, P. Clifton, R. Martens, Acta materialia 49 (2001) 4005.

[42] R. P. Elliott, Diffusion in titanium and titanium alloys, Armed Services Technical Information Agency ASD-TDR-62-561 (1962).

[43] N. L. Peterson, Diffusion in Refractory Metals, Wadd Technical Report WADD TR 60-793 (1960).

[44] H. Okamoto, Journal of phase equilibria 14 (1993) 266.

[45] Castro, José Fernando Ribeiro de, S.F. Santos, T. Ishikawa, W.J. Botta, Materials Research 15 (2012) 753.

[46] G. Thompson, R. Banerjee, H. Fraser, Appl. Phys. Lett. 83 (2003) 3471.

[47] Z.Y. Hang, C.V. Thompson, Acta Materialia 67 (2014) 189. 
Figure 1

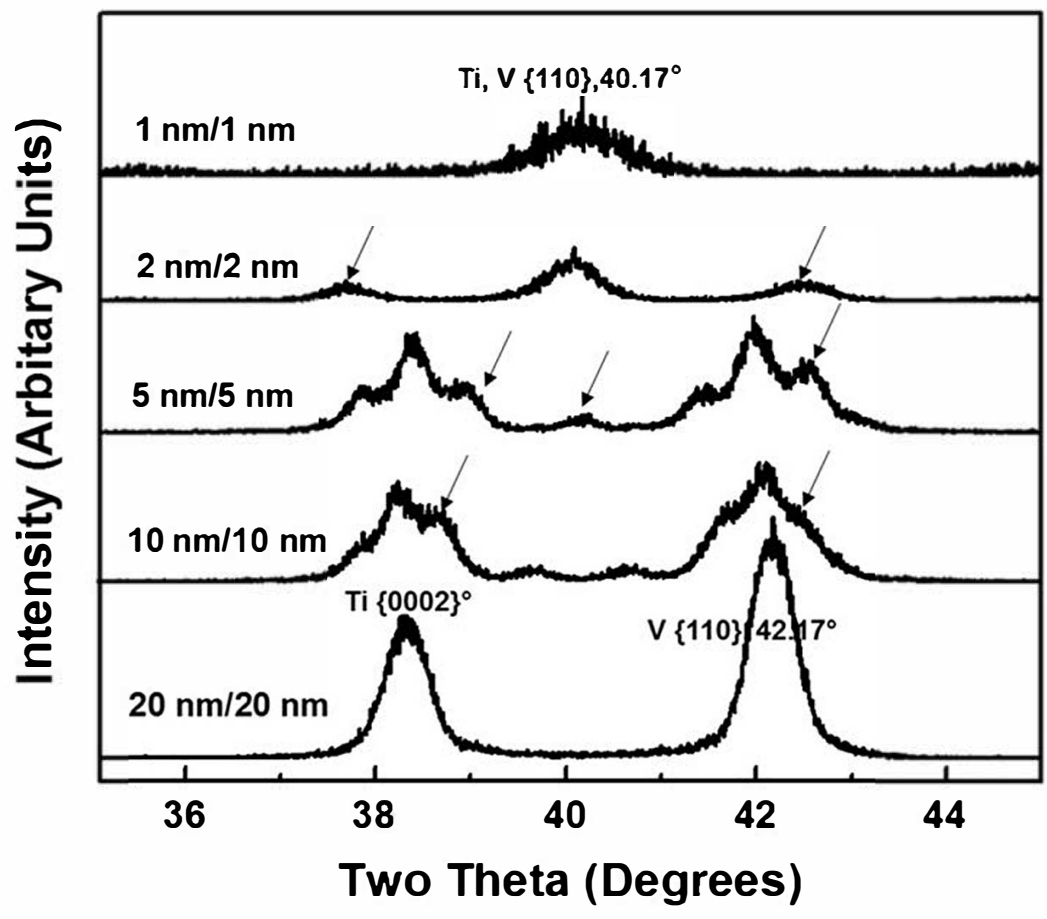


Figure 2

(a)

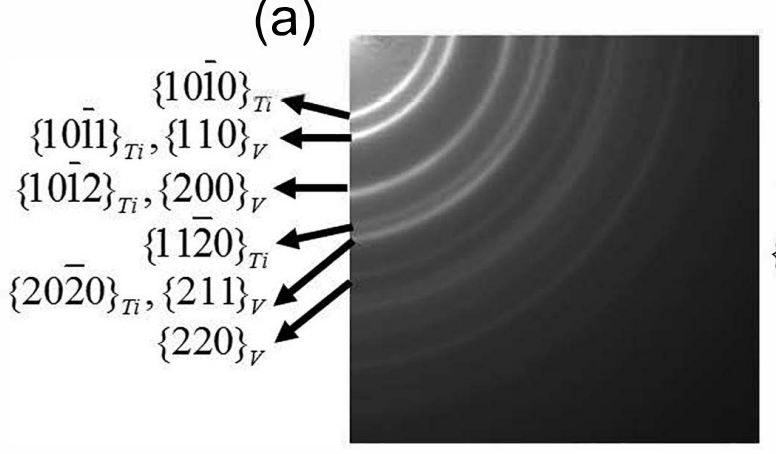

(d)

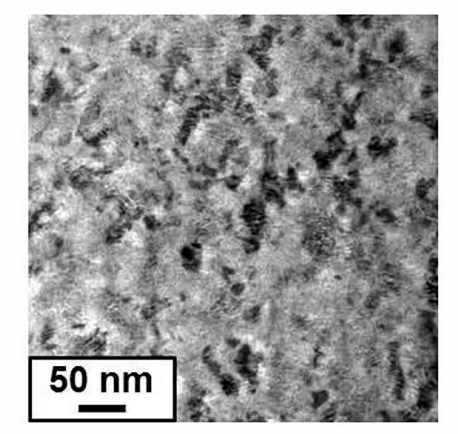

(b)

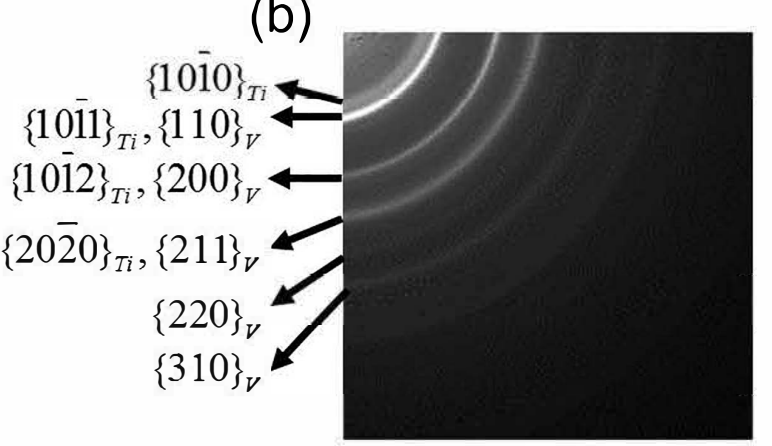

(e)

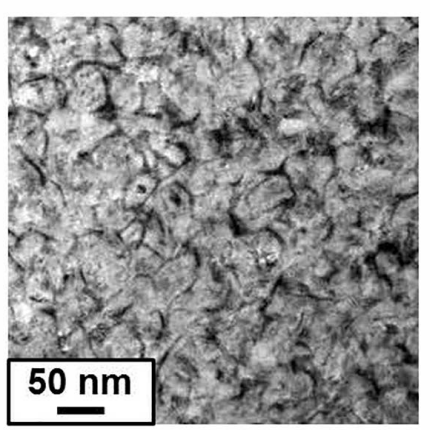

(c)

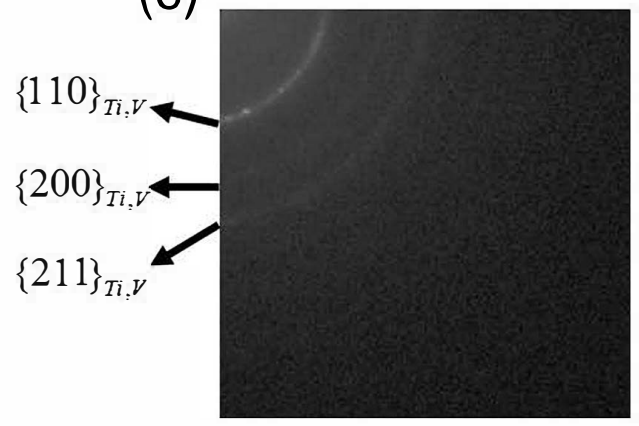

(f)

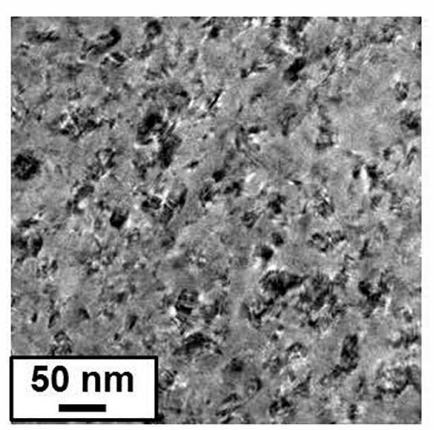




\section{Figure 3}

(a)

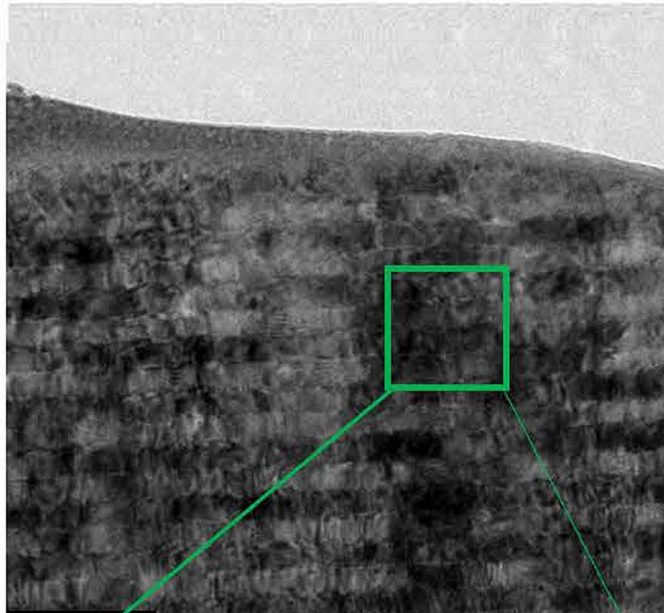

$20 \mathrm{gm}$

(b)

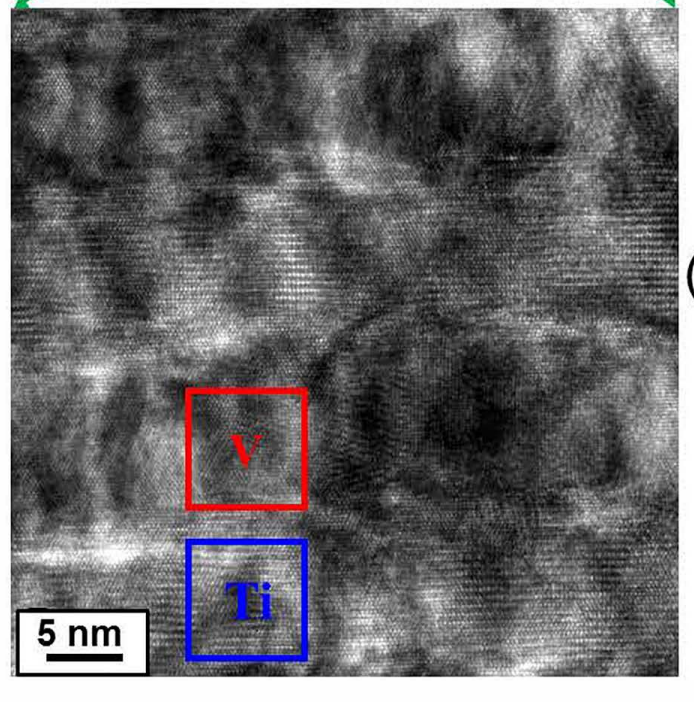

(c)

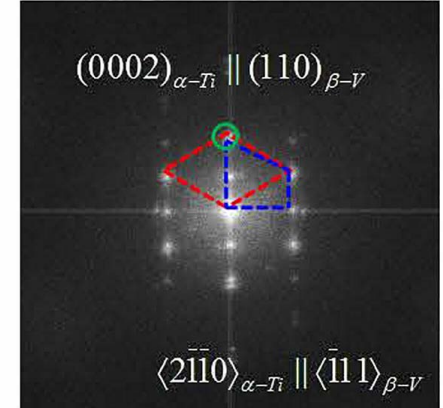

(d)

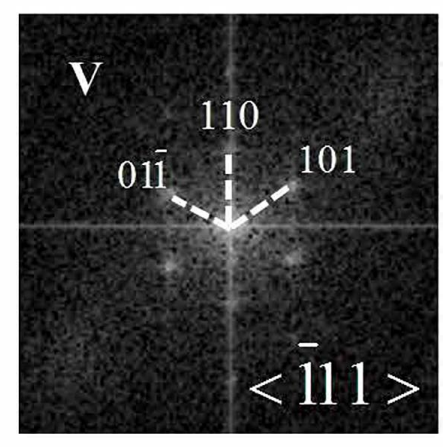

(e)

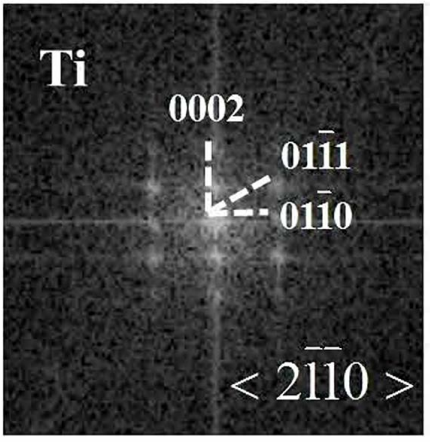

(f)

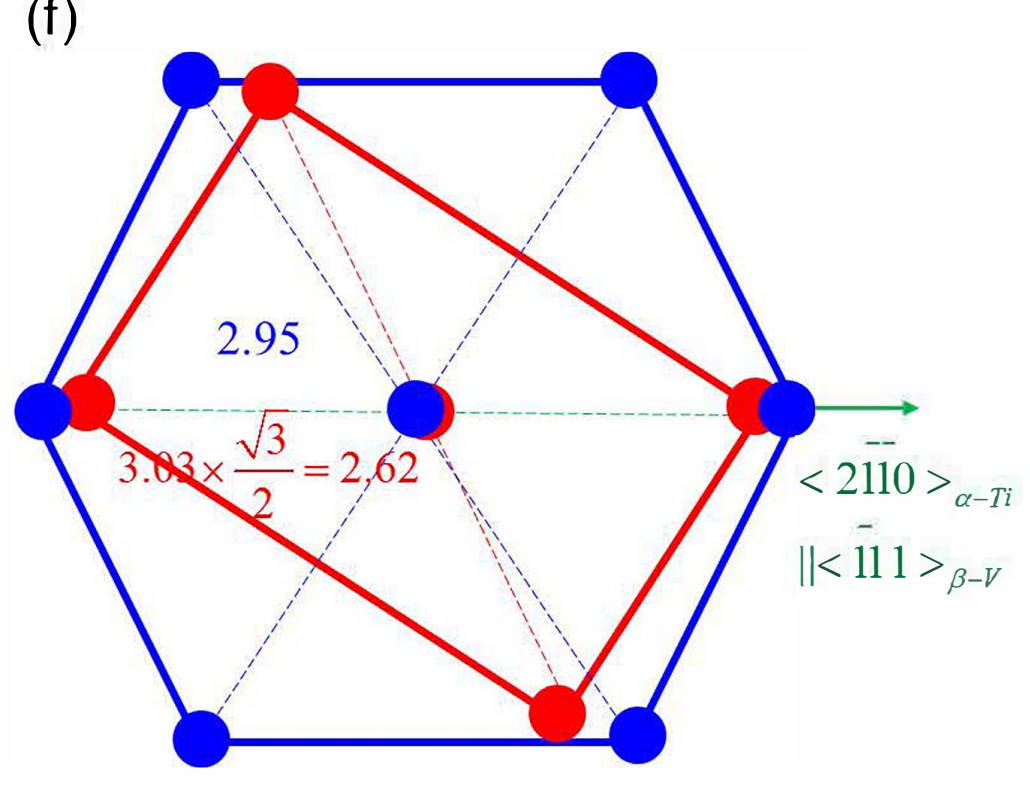




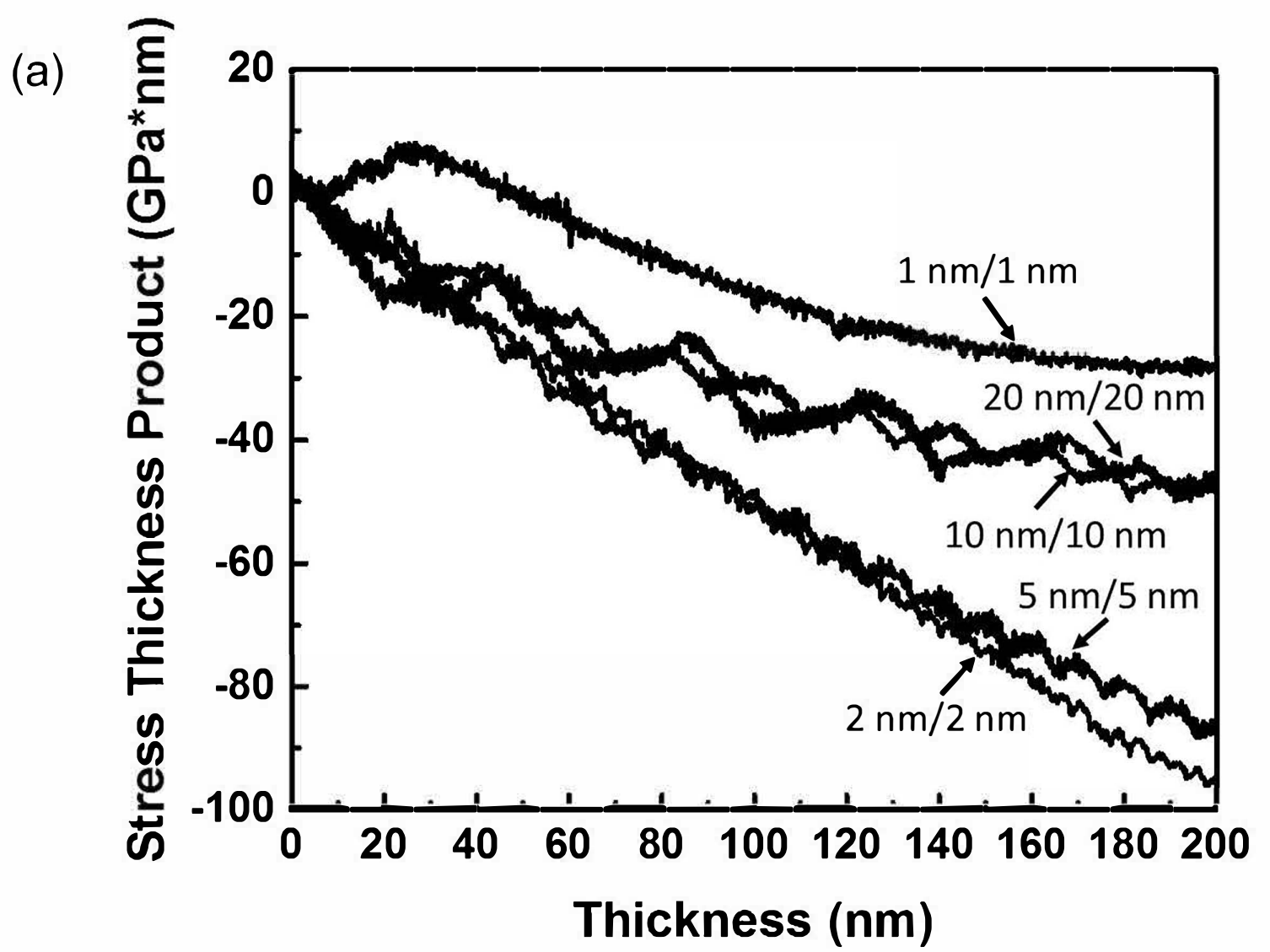

(b)

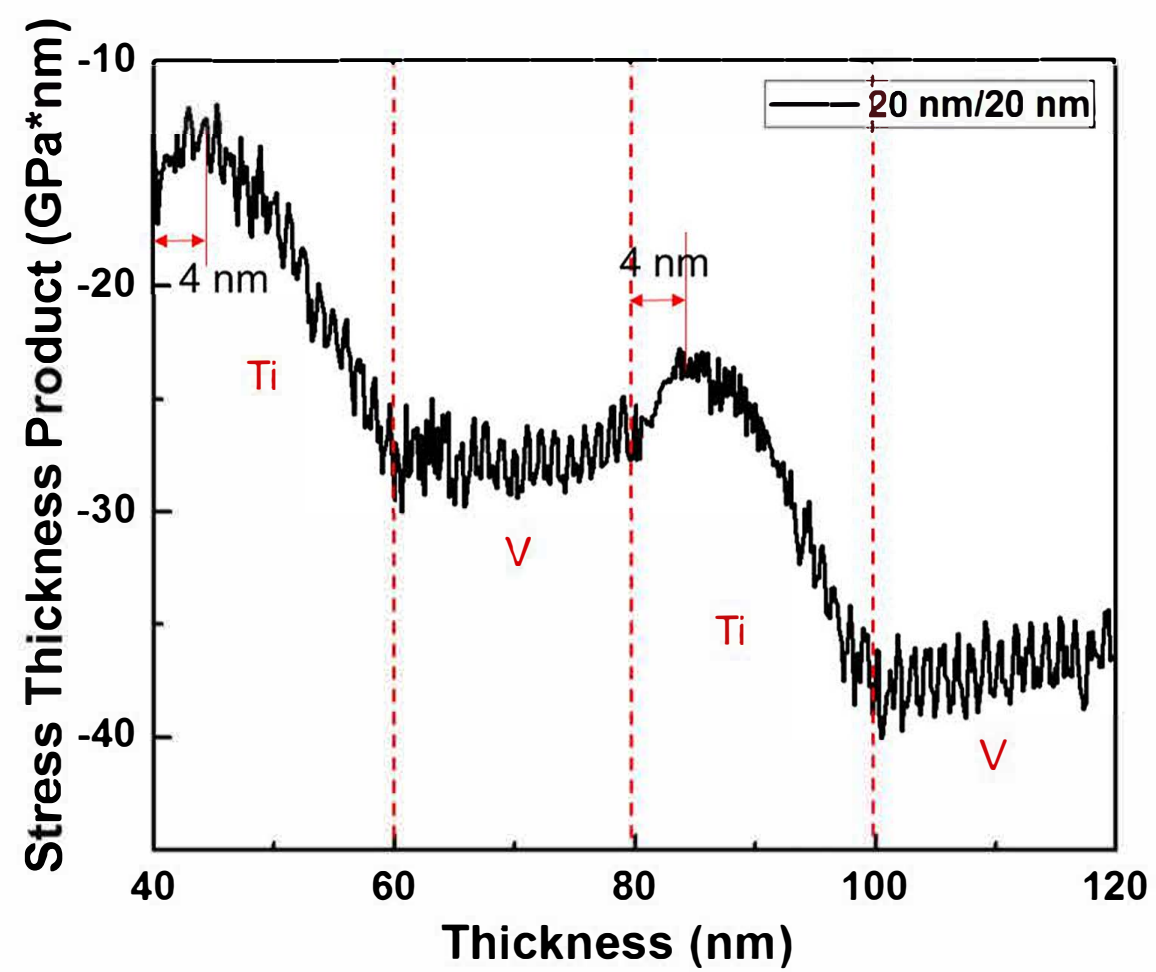

(d)

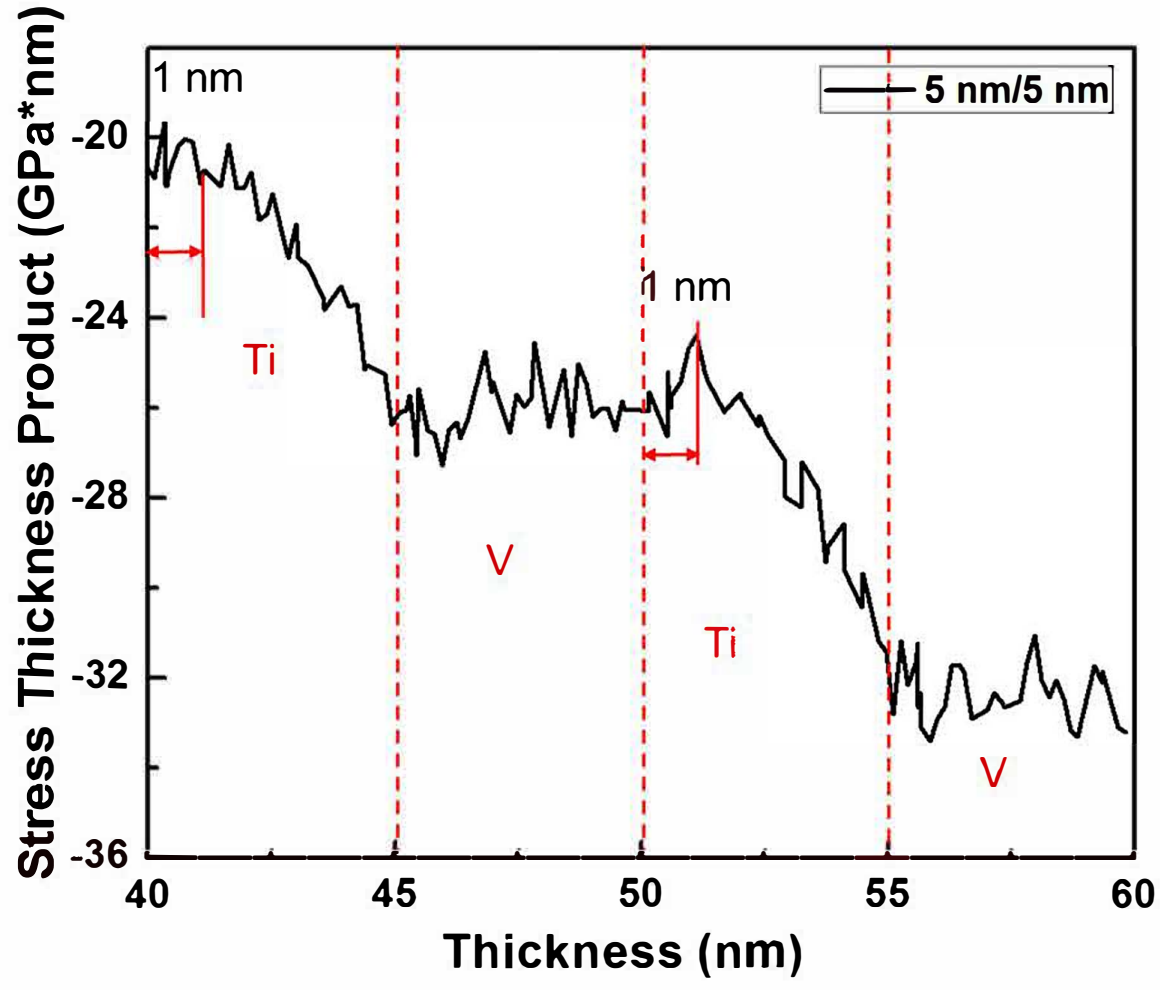

(c)

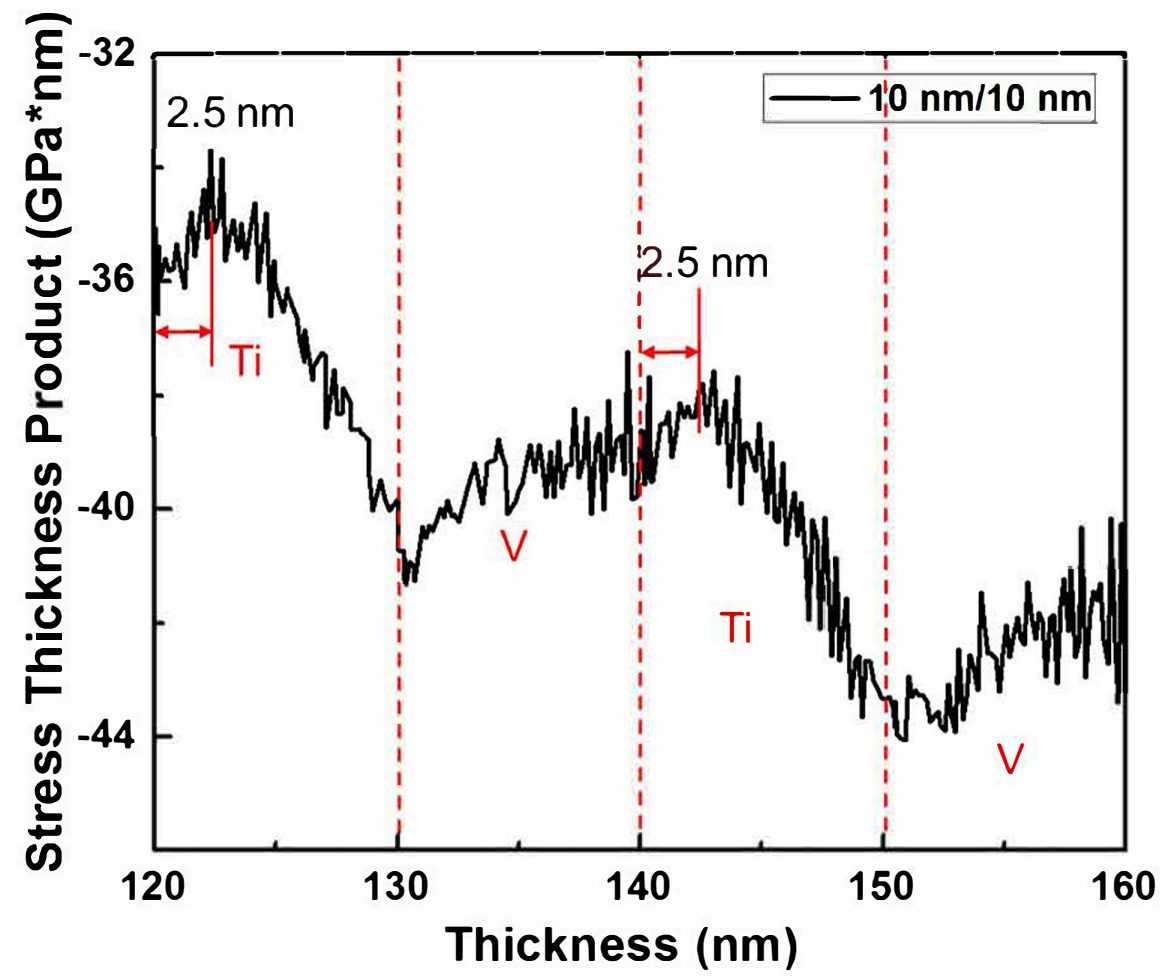

(e)

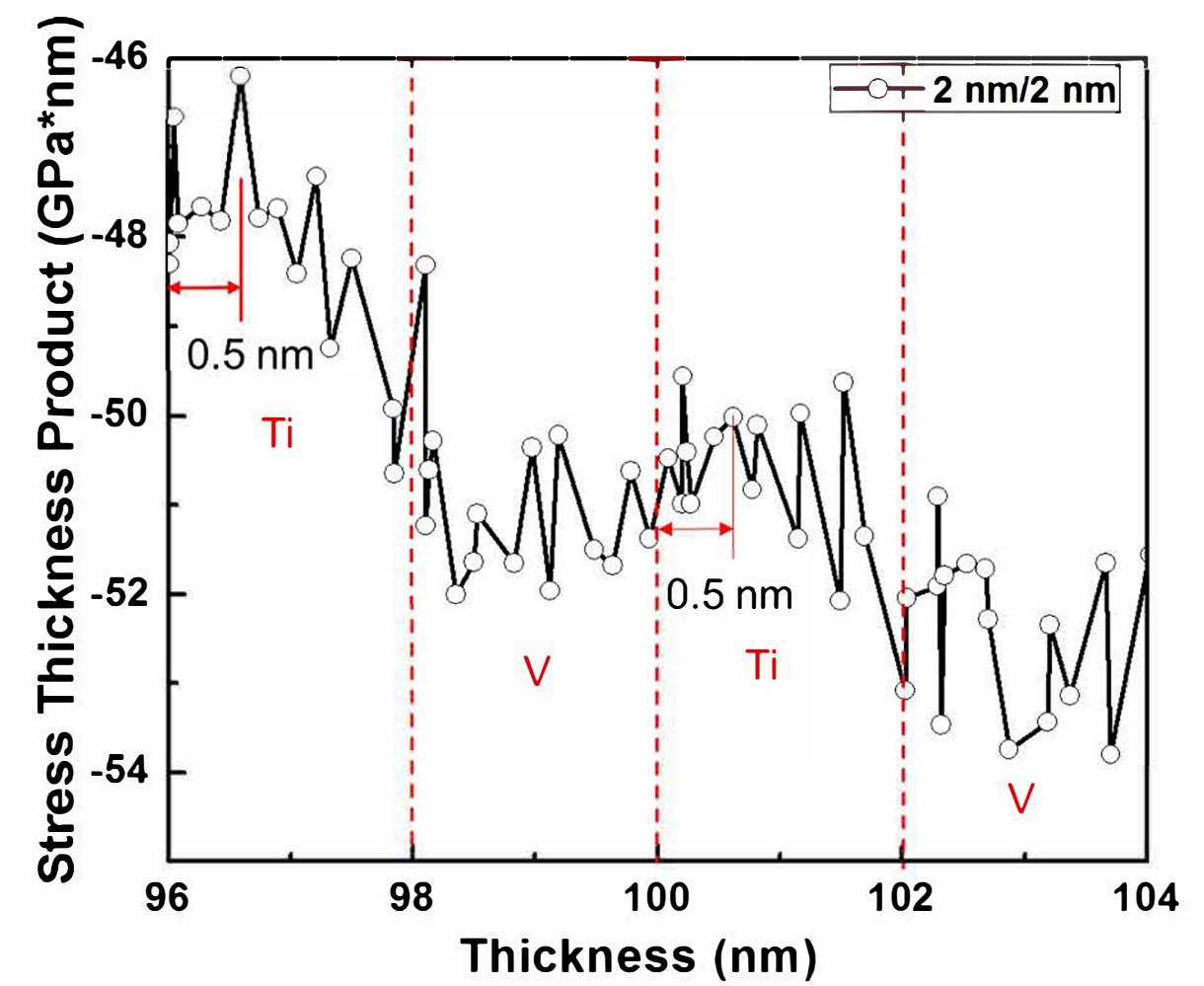


Figure 5

(a)
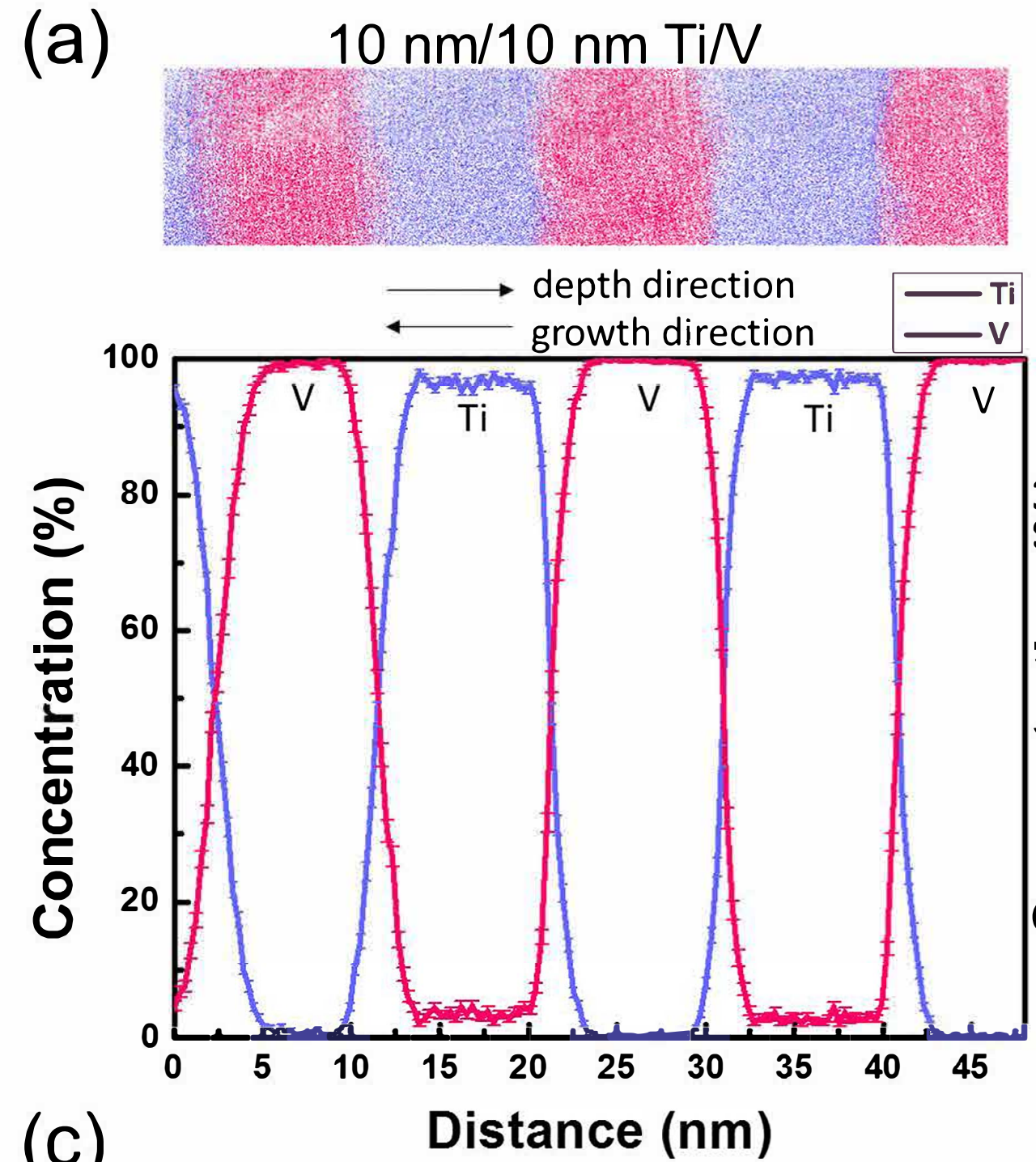

(c)

$2 \mathrm{~nm} / 2 \mathrm{~nm}$ Ti/V

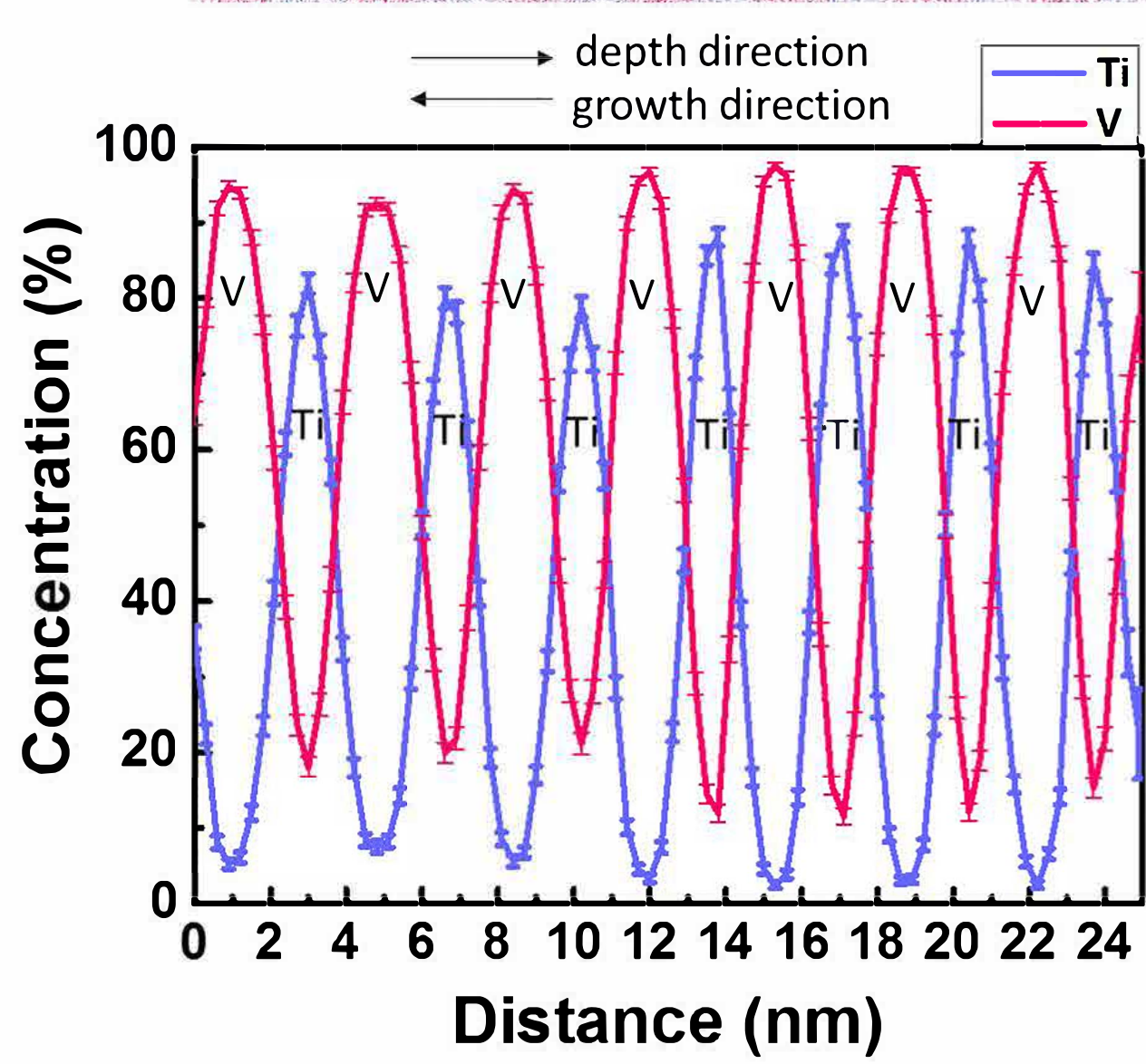

(b)

$5 \mathrm{~nm} / 5 \mathrm{~nm}$ Ti/V

Ti

- V

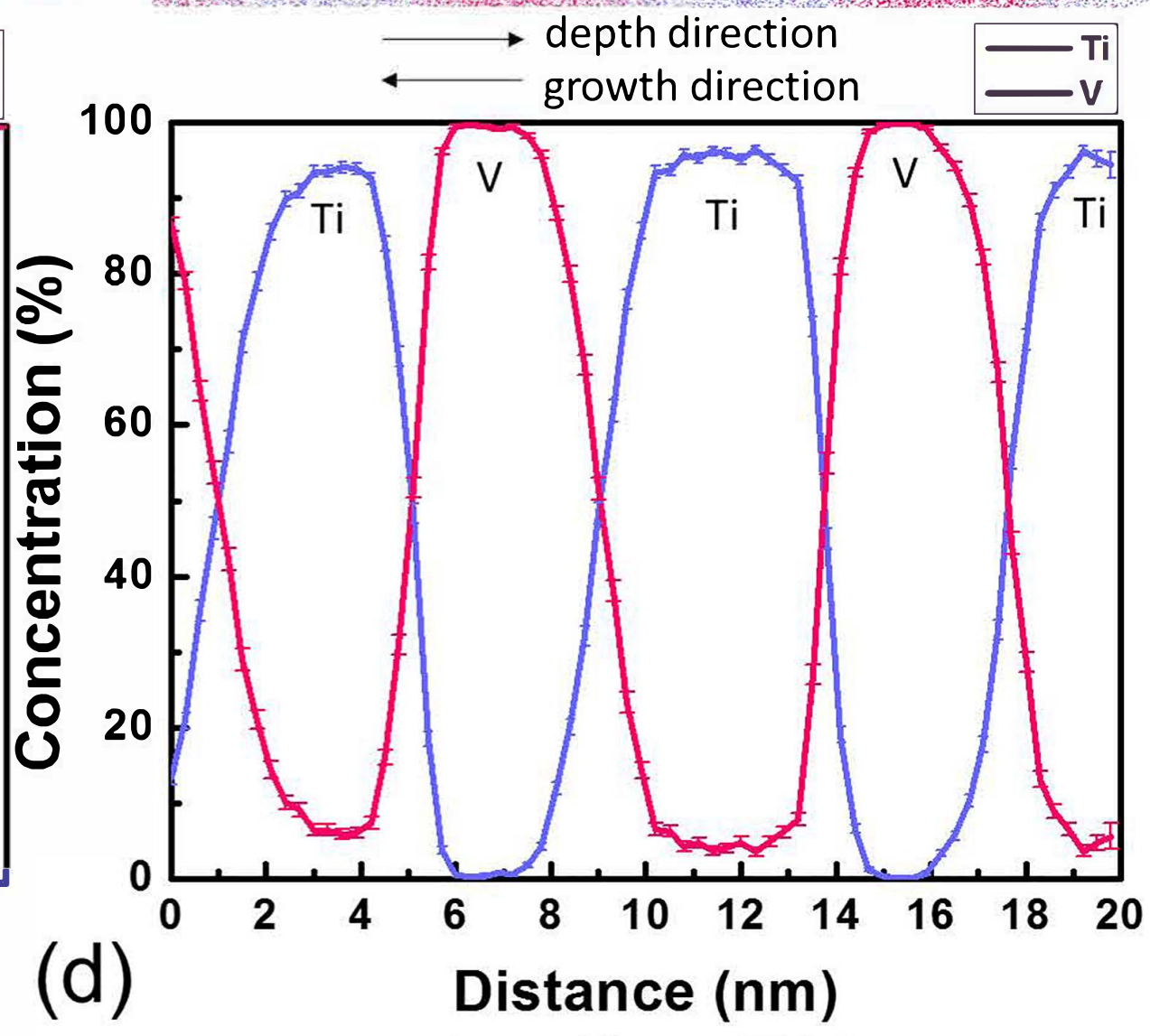

$1 \mathrm{~nm} / 1 \mathrm{~nm} \mathrm{Ti} / \mathrm{V}$
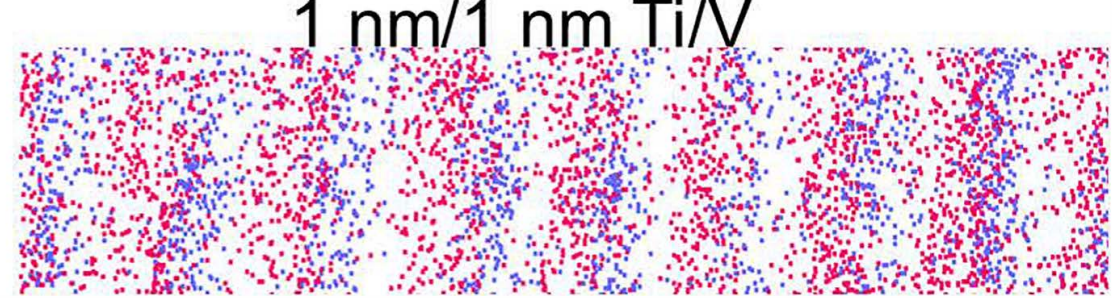

$\rightarrow$ depth direction

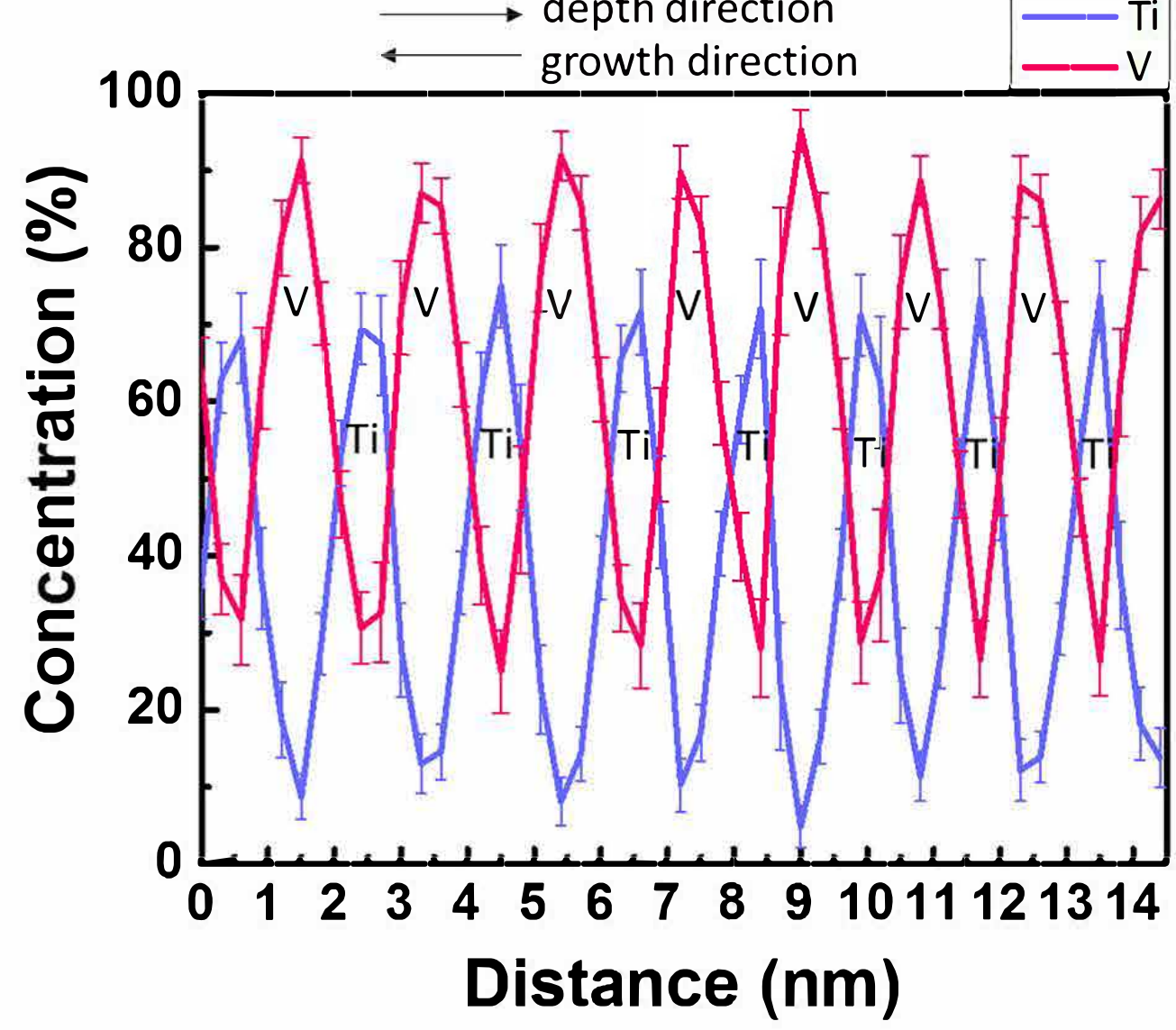


Table 1. Intermixing width at the interfaces and the Extent of $\mathrm{V}$ intermixing into the Ti layer

\begin{tabular}{cccc}
\hline $\begin{array}{c}\text { Layer thicknesses } \\
(\mathrm{nm} / \mathrm{nm})\end{array}$ & \multicolumn{2}{c}{ Intermixing width $(\mathrm{nm})$} & Extent of V intermixing \\
\hline $10 / 10$ & Ti on V & V on Ti & $3 \%$ \\
$5 / 5$ & $3.3 \pm 0.1$ & $3.9 \pm 0.3$ & $5 \%$ \\
$2 / 2$ & $1.5 \pm 0.1$ & $2.7 \pm 0.2$ & $15 \%$ \\
$1 / 1$ & $1.3 \pm 0.2$ & $1.4 \pm 0.1$ & $30 \%$ \\
\hline
\end{tabular}

Table 2. Lattice strain calculated from XRD

\begin{tabular}{|c|c|c|c|c|c|c|c|}
\hline \multirow[b]{2}{*}{$\begin{array}{c}\text { Layer } \\
\text { thicknesses } \\
(\mathrm{nm} / \mathrm{nm})\end{array}$} & \multicolumn{4}{|c|}{$\mathrm{Ti}$} & \multicolumn{3}{|c|}{$\mathrm{V}$} \\
\hline & $\begin{array}{c}\text { Ti } 2 \theta \\
\text { peak } \\
\text { position } \\
\left(^{\circ}\right)\end{array}$ & $\begin{array}{l}\mathrm{d}_{\mathrm{Ti}} \\
(\AA)\end{array}$ & $\begin{array}{l}\mathrm{Ti}\{0002\} \\
\text { strain }(\%)\end{array}$ & $\begin{array}{c}\operatorname{Ti}\{110\} \\
\text { strain }(\%)\end{array}$ & $\begin{array}{c}\mathrm{V} 2 \theta \\
\text { peak } \\
\text { position } \\
\left(^{\circ}\right)\end{array}$ & $\begin{array}{l}\mathrm{d}_{\mathrm{V}} \\
(\AA)\end{array}$ & $\begin{array}{c}\mathrm{V}\{110\} \\
\text { strain }(\%)\end{array}$ \\
\hline $20 / 20$ & 38.33 & 2.345 & 0.00 & N/A & 42.17 & 2.140 & 0.00 \\
\hline $10 / 10$ & 38.36 & 2.343 & -0.10 & N/A & 42.11 & 2.143 & 0.14 \\
\hline $5 / 5$ & 38.45 & 2.338 & -0.30 & N/A & 42.28 & 2.150 & 0.47 \\
\hline $2 / 2$ & 40.07 & 2.248 & -4.14 & -4.00 & 40.07 & 2.248 & 5.05 \\
\hline $1 / 1$ & 40.17 & 2.242 & N/A & -4.39 & 40.17 & 2.242 & 4.77 \\
\hline
\end{tabular}


Fig. 1 XRD scans of Ti/V multilayers. The $20 \mathrm{~nm} / 20 \mathrm{~nm}, 10 \mathrm{~nm} / 10 \mathrm{~nm}, 5 \mathrm{~nm} / 5 \mathrm{~nm}$ multilayers exhibit strong texture of $\mathrm{Ti}\{0002\}$ and $\mathrm{V}\{110\}$. The $2 \mathrm{~nm} / 2 \mathrm{~nm}$ and $1 \mathrm{~nm} / 1 \mathrm{~nm}$ multilayer showed a similar pattern while the single diffracted peak is ambiguous to determine the phase transformations.

Fig. 2 (a) Electron diffraction pattern of $10 \mathrm{~nm} / 10 \mathrm{~nm}$ multilayer. The distinctive hcp Ti rings, $\{10 \overline{10}\}$ and $\{1 \overline{2} 0\}$ confirmed this multilayer has a structure of hcp/bcc. (b) Electron diffraction pattern of $2 \mathrm{~nm} / 2 \mathrm{~nm}$ multilayer, a hazy $\{10 \overline{10}\}$ ring was shown while the $\{1 \overline{12} 0\}$ ring was not evident. (c) Electron diffraction pattern of the $1 \mathrm{~nm} / 1 \mathrm{~nm}$ multilayers. The disappearance of all the hcp ring and the rings present can only be indexed as bcc/bcc phases. (d)-(f) Representative plan-view TEM micrographs of $10 \mathrm{~nm} / 10 \mathrm{~nm}, 2 \mathrm{~nm} / 2 \mathrm{~nm}, 1 \mathrm{~nm} / 1 \mathrm{~nm}$ Ti/V multilayers.

Fig. 3 (a) TEM BF image of cross-sectional $10 \mathrm{~nm} / 10 \mathrm{~nm}$ Ti/V multilayer. (b) Magnified image from Fig. 3(a). The Ti and V layers are highlighted with the box. (c) Fast Fourier Transformation from the image in Fig. 3(b). Two sets of patterns were indexed and the zone axis was defined. (d) FFT taken from the V layer. (e) FFT taken from the Ti layer. (f) Burgers orientation relationship in $\mathrm{Ti} / \mathrm{V}$.

Fig. 4 (a) Stress evolution for $\mathrm{Ti} / \mathrm{V}$ multilayers with various bilayer thicknesses. (b)-(e) Magnified growth stresses for $20 \mathrm{~nm} / 20 \mathrm{~nm}, 10 \mathrm{~nm} / 10 \mathrm{~nm}, 5 \mathrm{~nm} / 5 \mathrm{~nm}$ and $2 \mathrm{~nm} / 2 \mathrm{~nm}$ multilayers, respectively.

Fig. 5 (a)-(d) Atom probe 1D concentration profiles from $10 \mathrm{~nm} / 10 \mathrm{~nm}, 5 \mathrm{~nm} / 5 \mathrm{~nm}, 2 \mathrm{~nm} / 2 \mathrm{~nm}$, and $1 \mathrm{~nm} / 1 \mathrm{~nm}$ films. Ion maps were shown above the profile. 